\title{
P061: Early detection and successful control of vancomycin resistant Enterococcus faecium (VRE) outbreak in an academic hospital in Pretoria, South Africa
}

RM Lekalakala ${ }^{1 *}$, E lewis $^{2}$, E Silberbauer $^{3}$

From 2nd International Conference on Prevention and Infection Control (ICPIC 2013)

Geneva, Switzerland. 25-28 June 2013

\section{Introduction}

Active surveillance which was introduced in 2008 following the Clostridium difficile outbreak in our hospital enhanced early detection of vancomycin resistant Enterococcus faecium out break in the medical intensive care unit (MICU). Prompt intervention strategies which were implemented by infection control team facilitated the successful control.

\section{Background}

A maximum of 10 VRE isolates per year has been the norm between 2008 and 2011 in our 800 bed hospital. These isolates were from the oncology units. Between the $4^{\text {th }}$ and $30^{\text {th }}$ August 2012, 7 patients in MICU had VRE positive cultures from a variety of samples including blood cultures.

\section{Methods}

Sample types and patient clinical data were collected; movement of infected patients within the hospital was traced to identify the possible index patient for patients who were not admitted directly into MICU. Hand washing and contact precautions practises were audited and reinforced as per VRE policy. Environmental cleaning audits were done routinely to minimize the bio burden and the unit was closed for new admission other than VRE positive patients. Infection control monthly reports were reviewed from May 2012 for possible oversight as there were no VRE cases in April. Monitoring and recording of new case is on-going with daily update to

${ }^{1}$ Medical Microbiology, NHLS \& University of Pretoria, Midrand, South Africa Full list of author information is available at the end of the article the team. One Isolate per patient is stored for molecular characterization.

\section{Results}

28 patients were identified over 10 months (May 2012 to February 2013). 42\% (12/28) patients from MICU, $25 \%$ (7/28) were dialysed. The environmental cleaning audit revealed a leaking sewage pipe in the MICU which resulted in a complete closure of the unit and immediate repairs which was followed by terminal cleaning of the whole unit.

\section{Conclusion}

It is well documented the most transmission of VRE is via contaminated hands of health care workers or environment or patient equipments. The findings in this study suggest that environmental contamination was the source of the VRE.

\section{Disclosure of interest}

None declared.

\section{Author details}

Medical Microbiology, NHLS \& University of Pretoria, Midrand, South Africa. ${ }^{2}$ IPC Division Steve Biko Academic Hospital, South Africa. ${ }^{3} \mathrm{NHLS} \&$ University of Pretoria, Pretoria, South Africa.

Published: 20 June 2013

doi:10.1186/2047-2994-2-S1-P61

Cite this article as: Lekalakala et al.: P061: Early detection and successful control of vancomycin resistant Enterococcus faecium (VRE) outbreak in an academic hospital in Pretoria, South Africa. Antimicrobial Resistance and Infection Control 2013 2(Suppl 1):P61.

\section{C)

(c) 2013 Lekalakala et al; licensee BioMed Central Ltd. This is an Open Access article distributed under the terms of the Creative Commons Attribution License (http://creativecommons.org/licenses/by/2.0), which permits unrestricted use, distribution, and reproduction in any medium, provided the original work is properly cited. 